\title{
Estado, Educação Superior e universidade no Brasil: processos de reconfiguração em tempos de reestruturação do capital
}

\author{
State, Higher Education and university in Brazil: reconfiguration processes in \\ times of capital restructuring \\ Estado, Educación Superior y universidad en Brasil: procesos de \\ reconfiguración en tiempos de reestructuración del capital
}

\section{SYLVANA DE OLIVEIRA BERNARDI NOLETO JOÃO FERREIRA DE OLIVEIRA}

\begin{abstract}
Resumo: Este artigo examina, por meio de análise bibliográfica e documental, alguns dos processos de reconfiguração da educação superior e das universidades públicas em particular, tendo por base a crise e as determinações da globalização do capital. Busca-se analisar as mudanças no papel do Estado brasileiro, as transformações em curso no capitalismo e a adoção dos princípios de diversificação e diferencial institucional que marcaram a reorientação da ação do Estado a partir da segunda metade dos anos 1990 em termos da estruturação, oferta e expansão da educação superior. Busca-se discutir ainda os rumos da universidade, sobretudo públicas, dado o processo de transformação de sua identidade e modus operandi na gestão, na produção do trabalho acadêmico, na formação e nos compromissos sociais que sempre estiveram presentes na sua constituição como instituição social.
\end{abstract}

Palavras-chave: Educação Superior; Universidade; Papel do Estado.

\begin{abstract}
This article examines, through bibliographical and documentary analysis, some of the processes of reconfiguration of higher education and public universities, in particular, based on the crisis and determinations of the globalization of capital. It seeks to analyze the changes in the role of the Brazilian State, the transformations underway in capitalism and the adoption of the principles of diversification and institutional differential that marked the reorientation of State action from the second half of the 1990s in terms of structuring, supply, and expansion of higher education. It also seeks to discuss the course of the university, especially public, given the process of transforming its identity and modus operandi in the management, production of academic work, educational process and social commitments that have always been present in its constitution as a social institution.
\end{abstract}

Keywords: Higher Education; University; Role of the State. 
Resumen: Este artículo examina, por medio de análisis bibliográfico y documental, algunos de los procesos de reconfiguración de la educación superior y de las universidades públicas en privado, teniendo como base la crisis y las determinaciones de la globalización del capital. Se busca analizar los cambios en el papel del Estado brasileño, las transformaciones en curso en el capitalismo y la adopción de los principios de diversificación y diferencial institucional que marcaron la reorientación de la acción del Estado a partir de la segunda mitad de los años 1990 en términos de la estructuración, oferta y la expansión de la educación superior. Se busca discutir aún los rumbos de la universidad, sobretodo públicas, dado el proceso de transformación de su identidad y modus operandi en la gestión, en la producción del trabajo académico, en la formación y en los compromisos sociales que siempre estuvieron presentes en su constitución como institución social.

Palabras clave: Educación Superior; Universidad; Papel del Estado.

\section{INTRODUÇÃO}

A crise conjuntural pela qual passa a Educação Superior brasileira está intimamente relacionada às últimas reformas e ações implementadas pelo Estado brasileiro, mas articulada à crise e aos interesses de acumulação do capital em âmbito mundial. A crise e tensionamento atuais têm por base o acirramento da implementação de um projeto ultraneoliberal e conservador que orienta a drástica redução da atuação do Estado na economia, na prestação de serviços públicos e na implementação de políticas sociais, com sua consequente adequação aos interesses do mercado e do capital, sobretudo financeiro.

O processo resultante de uma nova fase de reestruturação capitalista é marcado, no campo da Educação Superior, por políticas de diferenciação e de diversificação no tocante aos processos seletivos, organização acadêmica, tipos de cursos e modalidades, modos e processos de formação. Nesse contexto, parece sobreviver a instituição que melhor se ajustar aos novos modos de atuação do Estado e jogar o jogo mercadológico.

A par dessa configuração, o Estado e a Educação Superior no Brasil, embora sejam campos distintos, estão profundamente interconectados, uma vez que as instituições de Educação Superior (IES), sobretudo as públicas, são mantidas e reguladas pelos fundos públicos. Compreende-se que o campo da Educação Superior no Brasil, na contemporaneidade, é resultado do seu desenvolvimento histórico e das políticas empreendidas, produzidas e efetivadas em consonância com o desenvolvimento econômico e social do país. A Educação Superior é produto das lutas e posições de agentes desse campo específico, mas também da interconexão com outros campos sociais (político, econômico, poder 
etc.), que envidaram maiores ou menores esforços para a definição dos rumos e da implementação desse nível de educação. Como campo social, a Educação Superior se submete às relações de força e poder estabelecidas interna e externamente no espaço social. Conforme Bourdieu (2003), todo campo é um campo de forças, um campo de lutas para manter ou transformar esse campo de forças, comportando relações de dominação. Os agentes criam o espaço e esse espaço é construído diante de relações objetivas entre eles.

O artigo objetiva examinar alguns dos processos de reconfiguração da Educação Superior e das universidades em particular, tendo por base a crise e as determinações da globalização do capital e, para tanto, a metodologia adotada foi a pesquisa bibliográfica e documental. Nessa perspectiva, busca-se analisar as mudanças no papel do Estado brasileiro, as transformações em curso no capitalismo e a adoção dos princípios da diversificação e diferencial institucional que marcaram a reorientação da ação do Estado a partir da segunda metade dos anos 1990 em termos da estruturação, oferta e expansão da Educação Superior. Busca-se discutir, ainda, os rumos da universidade, sobretudo públicas, dado o processo de transformação de sua identidade e modus operandi na gestão, na produção do trabalho acadêmico, na formação e nos compromissos sociais que sempre estiveram presentes na sua constituição como instituição social.

\section{MUDANÇAS NO PAPEL DO ESTADO EM UM CONTEXTO DE REESTRUTURAÇÃO DO CAPITALISMO E DE ADOÇÃO DO MODO DE REGULAÇÃO NEOLIBERAL}

O desenvolvimento do capitalismo no mundo ocidental, de modo geral, vem sofrendo reestruturações e adaptações diante da própria organização dos Estados modernos em relação a contingentes internos e externos, em função da produção de distintas relações econômicas, políticas e sociais, dado um novo modo como as políticas são produzidas e desenvolvidas de maneira globalizada e com a indução do capital. (POCHMANN, 2017).

A crise do sistema capitalista gerada pelo esgotamento de seu regime de acumulação no final dos anos 1970 desencadeou a crise do denominado Estado do bem-estar social. A crise pode ser, também, concebida como ideológica na medida em que há uma acentuação naquilo que se analisa como problema para a manutenção de um Estado, daquilo que se deveria extrair do campo econômico e dispor ao campo social, ou seja, as decisões de se promover um ou outro investimento e gasto público estão assentadas no modelo de Estado ratificado por grupos que o mantêm e estão no poder, que têm uma ideologia e um entendimento sobre o Estado e suas funções. 
A "globalização ultraliberal" em curso apresenta processos e dimensões múltiplas que expressam o caráter complexo, difuso e articulado de uma nova fase do capital, de uma nova etapa de acumulação, exploração e expansão do sistema. Essa nova fase implica modificações nas condições em que se processam as políticas mundiais e locais. Observam-se contradições no movimento de globalização do capitalismo, uma vez que este produz ambiente e estratégias para a dominação política e apropriação econômica de abrangência mundial; conformamse, nesse movimento, novas relações de sociabilidade ao custo da reconfiguração e adaptação de forças sociais em processos de lutas, da reconfiguração de estruturas de poder nos campos econômicos, políticos, culturais e sociais, em especial dos países do Ocidente (DARDOT; LAVAL, 2017; SGUISSARDI, 2015)

O Estado liberal, ou Estado neoliberal, desde sua constituição histórica, tem representado de forma dissimulada os interesses privados ou privadomercantis, utilizando-se de estratégias de convencimento e coerção na busca pelo consenso ideológico desses grupos. Harvey (2011) e Chesnais (1996) convergem sobre o entendimento do neoliberalismo e o compreendem como práticas políticas e econômicas que buscam por lucro, incluindo a financeirização, a manipulação de crises e a intensificação das ações de privatização. Essas práticas atingem de modo diferenciado cada uma das regiões do mundo, seguindo uma dinâmica geograficamente desigual de acumulação, conforme os autores. Por sua vez, Bourdieu (1998, p. 82) acentua o caráter político e econômico do neoliberalismo, que instaura a desigualdade social entre países e regiões.

\footnotetext{
Efetivamente, o discurso neoliberal não é um discurso como os outros. [...], é um "discurso forte", que só é tão forte e tão difícil de combater porque tem a favor de si todas as forças de um mundo de relações de força, que ele contribui para fazer tal como é, sobretudo orientando as escolhas econômicas daqueles que dominam as relações econômicas e acrescentando assim a sua força própria, propriamente simbólica, a essas relações de força. Em nome desse programa científico de conhecimento convertido em programa político de ação, cumpre-se um imenso trabalho político (renegado, pois aparentemente puramente negativo) que visa [a] criar as condições de realização e de funcionamento da "teoria"; um programa de destruição metódica dos coletivos (a economia neoclássica querendo lidar apenas com indivíduos, mesmo quando se trata de empresas, sindicatos ou famílias). (grifos nossos).
}

O neoliberalismo, conforme Bourdieu (1998), institui-se como "programa político de ação" e promove o discurso sobre a importância da democratização dos espaços públicos com a participação de agentes coletivos e das comunidades ao mesmo tempo que promove "um programa de destruição metódica dos coletivos". Complementando-se a essa perspectiva, compreende-se que, por dentro das estruturas institucionais, o neoliberalismo desenvolve acirradamente 
o projeto de desarticulação dos coletivos e de individualização; ratifica o discurso sobre a garantia dos direitos, porém, com a prerrogativa do mérito pela competência; há uma acentuação sobre os processos de desigualdade social que determinam os lugares ocupados pelos coletivos, indivíduos e instituições. Nessa perspectiva, a democracia transforma-se em um valor instrumental e não substancial, desenvolvida sob a égide da racionalidade instrumental, técnica e de resultados. E, nessas questões, o Estado neoliberal se institui com força e poder, pois está do lado do capital, media relações econômicas e políticas voltadas à expansão do capital.

Segundo Wood (2011), é possível pensar que há uma articulação estratégica dos países capitalistas para a separação entre capitalismo e democracia, ou seja, em que as democracias modernas, tomando-se como exemplo os EUA, não conservam aquilo que de fato constituiu a democracia grega: a coletividade ativa e direta. Para Wood (2010, p. 407), "O capitalismo é - em sua análise final incompatível com a democracia, se por democracia entendemos tal como o indica sua significação literal, o poder popular ou o governo do povo.” (grifos nossos). A ideia de povo, nesse sentido, é tida como abstração e resultado desse modelo; aqui já não é o corpo social, a coletividade que aparece em primeiro plano, mas, sim, o indivíduo, que atua sozinho. Como estratégia complexa, isso gera um processo de despolitização da sociedade, separando política e capitalismo e, ao contrário, estabelecem-se condições para uma relação tolerável entre democracia e capitalismo. Essa relação tensa e certamente tênue, põe em questão a legitimidade das políticas sociais, uma vez que a ideia de indivíduo atribui a cada um a responsabilidade ou competência de manter-se na vida, de lutar concorrencialmente pelo seu bemestar. O indivíduo está separado da coletividade, da organização coletiva. Esse ideário se agrega aos fundamentos que põem em xeque as possibilidades do Estado social.

Nessa direção, Pochmann (2017) faz uma análise sobre o papel e função do Estado e evidencia os contextos internos e externos das relações políticas e econômicas que nosso país desenvolveu ao longo das últimas três décadas. Como limite, o Estado que evidencia e desenvolve políticas sociais expressivas esbarra na resistência dos setores privados quando ocorre a diminuição da rentabilidade das empresas, queda da taxa de juros, o que naturalmente gera a diminuição da disposição em investir, em especial pela percepção subjetiva das empresas, à medida que há implementação exitosa dos programas sociais empreendidos pelo Estado. Para tanto, o Estado, para sua progressão e continuidade, tem que deixar intacto o modo de funcionamento do sistema econômico, o que só é possível se exercer influência sobre a atividade privada de investimentos, ajustando-a ao sistema; quando há ajuste ao sistema capitalista, ocorre a possibilidade de sua 
não efetivação, há desvirtuamento por meio das necessárias adesões e relações com o capital econômico. Pochmann (2017, p. 311) confirma que "O processo de desenvolvimento capitalista brasileiro constituiu-se assentado direta e indiretamente na atuação do Estado, sobretudo pela natureza das formações sociais ambientadas na tradição autoritária e de transição tardia". Entende, ainda, que o Estado brasileiro é por excelência interventor, na medida em que se estruturou no período republicano com um conjunto complexo e extraordinário de organizações estatais instituídas para executar políticas públicas, administrar um montante expressivo de despesas na diversidade do seu sistema de financiamento. Reafirma que as "Relações estabelecidas pelo Estado no desenvolvimento capitalista brasileiro, os modos de intervenção encontram limites nas exigências da acumulação de capital." (POCHMANN, 2017, p. 311).

Em outro sentido, de toda forma importante às questões apresentadas, Carnoy (1988, p. 306) observa que há também aqueles que não consideram as classes, que veem a crise ou em termos de 'excesso de Estado' ou de 'excesso de democracia'. Nesse entendimento, o Estado se torna um problema para o desenvolvimento do capital. E analisa que essas posições ou visões consideram "Que o problema não reside absolutamente na natureza do capitalismo, mas na extensão em que o Estado, seja como uma entidade autônoma com seu próprio poder ou como representante das massas, interfere 'irracionalmente' no desenvolvimento capitalista". Conforme o autor, para ambas as razões existem respostas políticas, ou seja, onde o Estado é autônomo e irracional a resposta é diminuir a interferência ou presença do Estado reprivatizando a economia e a sociedade; no outro caso, onde a irracionalidade do Estado resulta não de sua autonomia, a resposta é ampliar o papel do Estado, mas para separá-lo da influência das massas.

Segundo Pochmann (2017, p. 313), no entanto, “As determinações na forma de atuação do Estado servem tanto às exigências da estrutura de competição intercapitalista quanto ao formato da dominação exposta pelo centro dinâmico capitalista à periferia global" (grifos do autor). Ou seja, o capital internacional procura resolver sua crise exportando-a para a periferia. O Brasil é da periferia do capital e, portanto, mantém relações de subserviência aos grandes centros capitalistas. É interessante observar o que significa ser da periferia do capitalismo, ou seja, não ser ou estar no centro. Significa ser o outro, ser aquele que não é reconhecido como civilizado (como o que pode ser colonizado). É, portanto, aquele colonizável, aquele que deve estar submetido ao poder de um outro maior, melhor e mais capitalizado. Conforme Teixeira (2006, p. 539, grifos do autor), "O sentido da colonização é, portanto, a constituição da periferia de um sistema capitalista mundial". 
A partir de Fernando Collor de Melo (1990-1992) na Presidência da República, aprofunda-se o projeto de inserção dependente do Brasil na economia mundial alicerçada nas forças do mercado, calcada na liberalização, na flexibilização, na desregulação, na reestruturação produtiva, com um caráter fortemente conservador e que se espraia sobre toda a sociedade, inclusive sobre a educação. Nesse período, intensificou-se o processo de liberalização da economia, liberalização forçada pelo grande capital internacional, que, encontrando-se em crise, avalizado pelos governos e elites nacionais, penetrou fortemente no mercado interno. Com isso, buscou-se ampliar as privatizações, promoveram-se reformas nas áreas sociais, administrativas, educacionais, previdenciária e trabalhista.

No contexto atual observa-se, conforme Pochmann (2017, p. 311), que o aparelho estatal se modificou juntamente com o processo atual de desindustrialização. E explica: “Assim, pela expansão capitalista, o Estado se transforma concomitantemente com o avanço e diferenciação das classes sociais e suas frações em disputa pelo controle do aparelho estatal e de atuação na economia e na sociedade nacional". Compreende-se aqui que o Estado, ao mesmo tempo que é sujeitado ao sistema capitalista porque se mantém como instituição que ratifica o capital, também promove violência física e simbólica sobre as instituições sociais e agentes sociais que o constituem. É interessante observar a construção gradativa do papel e função do Estado brasileiro mediante as articulações dos grupos econômicos, dos interesses da elite brasileira em detrimento das camadas populares. Desde o impeachment da presidenta Dilma Rousseff, em 2016, há uma inflexão nas políticas públicas instauradas o que pode ser denominado "ciclo político ${ }^{1}$ da Nova República”. (POCHMANN, 2017).

No entendimento de Mancebo, Silva Jr. e Oliveira (2018, p. 02),

No Brasil, foram abaladas as próprias bases sociais da reprodução política, cujo destaque foi o impeachment da presidenta eleita Dilma Rousseff, que veio a ser substituída pelo vice-presidente Michel Temer por decisão do Congresso Nacional. Assim, o Brasil vive mais uma ruptura democrática, acompanhada por uma grave crise política, econômica e social. [...] Obviamente, essa conjuntura afeta todas as instituições republicanas e, sobremodo, as instituições de Educação Superior (IES), assim como as políticas e ações que estavam em curso no tocante a este nível de ensino, a exemplo das metas e estratégias previstas no Plano Nacional de Educação (2014-2024), aprovado pela Lei n. 13.005, de 25 de junho de 2014 (Brasil, 2014).

Avalia-se que as reformas implementadas desde então alteram o papel do Estado no capitalismo brasileiro, reposicionando-o frente ao centro dinâmico capitalista mundial, em que se constata que se estrutura no interior do Congresso Nacional e do poder executivo federal, sobretudo no período pós-impeachment 
da presidenta Dilma Rousseff, uma maioria política favorável aos interesses das classes dominantes, em consonância com os interesses do capital internacional. As mudanças no papel do Estado vêm sendo, pois, cada vez mais ajustadas à hegemonia do capital financeiro internacional, tendo por base a adoção de diretrizes da regulação ultraneoliberal, associadas a preceitos ultraconservadores, especialmente nos costumes da vida social.

\section{A REESTRUTURAÇÃO DA EDUCAÇÃO SUPERIOR NO BRASIL: O PROCESSO DE DIVERSIFICAÇÃO E DIFERENCIAÇÃO INSTITUCIONAL E O PAPEL DA UNIVERSIDADE EM QUESTÃO}

Tomar a Educação Superior como campo social, ou, mesmo, um subcampo da educação é buscar entendê-la como um lócus que abriga agentes institucionais, sujeitos coletivos e individuais, agentes de modo geral, que se movem e se relacionam entre si como agentes e com outros campos sociais, que, em boa medida, desenvolvem habitus que moldam o dia a dia do campo ${ }^{2}$. Como campo social de relações objetivas, a Educação Superior se constitui em processo histórico que produz, lenta e progressivamente, sua autonomização como campo, numa espécie de depuração, ou seja, as lutas que têm lugar no campo vão depurando os lugares, as posições dominantes dos agentes, e mais, os princípios que sustentam a evidenciação e conformação dos elementos presentes no campo. Nesse sentido, o microcosmo aqui definido como campo, a Educação Superior, também se limita a leis sociais próprias que o definem e o caracterizam como campo social, com agentes e instituições sociais que estão ali incluídas em relações de força e poder, na premissa de pertencimento ao campo, de disposições incorporadas, bem como de ocupação de lugar. Esse microcosmo desenvolve uma autonomia parcial mais ou menos acentuada em sua relação com o macrocosmo e como resultado do movimento interno de seus agentes e instituições.

Como um objetivo identificável comum dos agentes institucionais da Educação Superior no campo pode-se destacar a formação de indivíduos em nível superior. E, nesse âmbito comum, pode-se fazer um recorte entre os agentes do campo da Educação Superior, destacando os agentes institucionais denominados IES, observando-se sua presença, posição e forma de atuação no campo. A partir 
disso, analisa-se que os agentes institucionais no campo da Educação Superior se diferenciam à medida que se desenvolvem com estruturas e estratégias específicas, bem como com estratégias que agrupam alguns em detrimento de outros ou, mesmo, em que essa especificidade qualifica e garante espaço, lugar, posição, manutenção e até mesmo distinção no campo. A diferenciação expressiva no campo da Educação Superior pode ser visualizada a partir da configuração organizativa dos modelos de instituições de ensino, ou seja, cada modelo resulta de lutas contingenciais e históricas para sua afirmação.

Saviani (2000, p. 49) explicita, a partir do Decreto $\mathrm{n}^{\circ}$ 2.306/1997 (BRASIL,1997), que "a proposta ou estratégia oficial de diferenciação institucional e diversificação de fontes financeiras como parte da solução para os males históricos da Educação Superior brasileira apresenta, portanto, dimensões variadas". Ou seja, a categorização das IES no Brasil instituída pelo Decreto no 2.306/1997, que introduziu modificações no sistema de Educação Superior, especialmente quanto à natureza e dependência administrativa, definiu nova disposição acadêmica que desenhou-se pela identificação das IES como: a) Instituições Universitárias constituídas de Universidades; Universidades Especializadas e Centros Universitários; b) Instituições não universitárias, compostas por Centros Federais de Educação Tecnológica (CEFET) e Centros de Educação Tecnológica (CET), Faculdades Integradas, Faculdades Isoladas e Institutos Superiores.

No processo de diferenciação das IES a partir de 1997, o que se pode depreender é a necessidade de se estabelecer um caráter regulatório para as instituições, no sentido de agrupá-las em organizações acadêmicas mais definidas. O que se verifica é a franca diferenciação e diversificação, mesmo dentro dos agrupamentos de instituições classificadas, ou seja, há uma gama de características que denotam sua diversificação, mesmo sendo classificadas para o mesmo grupo de organização acadêmica. "No Brasil, os modelos institucionais seguiram a tipologia ou ideia (isomorfismo mimético?) de muitos outros existentes no mundo que valorizaram a diversificação institucional.” (LEITE, 2006).

DiMaggio e Powell (2005) compreendem que as instituições se conformam a um campo organizacional e identificam que elas se reconfiguram, promovem mudanças de si, transformam-se, sob os mecanismos do isomorfismo institucional. Os autores identificaram três mecanismos por meio dos quais ocorre a mudança isomórfica institucional. O primeiro deles, o isomorfismo coercitivo, é resultado da dependência e das expectativas culturais que determinadas organizações exercem sobre outras; isto é, são forças formais e informais que algumas organizações exercem sobre outras, influenciando suas estruturas organizacionais. O segundo mecanismo é o isomorfismo mimético. O último mecanismo de mudança isomórfica institucional refere-se às pressões normativas. 
Conforme Neves (2003), o recente desenvolvimento da Educação Superior no país expõe a contradição vivida pelo sistema: pressionado a expandirse e diversificar-se, é também pressionado a manter o isomorfismo. Barreyro (2008, p.22), por sua vez, acentua a questão da diversificação entre as IES, ao explicitar que

O artigo 45 da LDB permitiu a diversificação das instituições; sua regulamentação pelo Decreto n 2.306/97 do Presidente da República, tornou possível a criação de diferentes organizações acadêmicas autorizadas a ministrar Educação Superior. Essas formas: centros universitários, faculdades integradas, faculdades e institutos ou escolas superiores podem educar sem precisar desenvolver as funções indissociáveis de ensino, pesquisa e extensão que as universidades devem cumprir, como postula a Constituição (art. 207). Assim, o Centro Universitário gozava de autonomia para criar novos cursos sem o ônus da indissociabilidade entre ensinopesquisa e extensão que é mais cara. (grifos da autora).

Mais recentemente, a categorização das IES no Brasil foi reconfigurada pelo Decreto ${ }^{\circ}$ 9.235/2017, que em seu Art. 15, incisos I, II e III, $\$ 4^{\circ}$, estabeleceu que:

Art. 15. As IES, de acordo com sua organização e suas prerrogativas acadêmicas, serão credenciadas para oferta de cursos superiores de graduação como: I faculdades; [...] II - centros universitários; e [...] III - universidades. [...] $\int 1^{\circ}$ As instituições privadas serão credenciadas originalmente como faculdades. [...] $₫ 2^{\circ} \mathrm{A}$ alteração de organização acadêmica será realizada em processo de recredenciamento por IES já credenciada. [...] $\int 3^{\circ}$ A organização acadêmica das IFES é definida em sua lei de criação. [...] \ $4^{\circ}$ As instituições da Rede Federal de Educação Profissional, Científica e Tecnológica são equiparadas às universidades federais para efeito de regulação, supervisão e avaliação, nos termos da Lei no 11.892 , de 29 de dezembro de 2008 .

As IES são classificadas em públicas e privadas quanto a sua competência e responsabilidade, assim como podem ser observadas instituições universitárias e não universitárias. A Educação Superior, no conjunto das instituições universitárias e não universitárias, diferencia-se, no ano de 2017, como expresso no Quadro 1, a seguir. 


\section{Quadro 1 - Quantitativo de IES no Brasil por Categoria Administrativa em 2017}

\begin{tabular}{|c|c|c|c|c|c|c|c|c|c|c|c|c|c|c|c|}
\hline \multirow{2}{*}{$\begin{array}{l}\text { Categoria } \\
\text { Adminis- } \\
\text { trativa }\end{array}$} & \multicolumn{15}{|c|}{ INSTITUIÇÕES } \\
\hline & Total & Capital & Interior & Total & Capital & Interior & Total & Capital & Interior & Total & Capital & Interior & Total & Capital & Interior \\
\hline Brasil & 2.448 & 874 & 1.574 & 199 & 86 & 113 & 189 & 79 & 110 & 2.020 & 679 & 1.341 & 40 & 30 & 10 \\
\hline Pública & 296 & 96 & 198 & 106 & 49 & 57 & 8 & 1 & 7 & 142 & 18 & 124 & 40 & 30 & 10 \\
\hline Municipal & 63 & - & 63 & 4 & - & 4 & 7 & - & 7 & 52 & - & 52 & - & - & - \\
\hline Privada & 2.152 & 776 & 1.376 & 93 & 37 & 56 & 181 & 78 & 103 & 1.878 & 661 & 1.217 & - & - & - \\
\hline
\end{tabular}

Fonte: BRASIL/MEC/INEP - Sinopse Estatística da Educação Superior 2017

Disponível em http://inep.gov.br/web/guest/sinopses-estatisticas-da-educacao-superior . Acesso 05 de maio de 2019.

Observa-se no Quadro 1 que, no conjunto das IES no Brasil (2.448), há a prevalência de IES privadas (2.152) equivalendo a 87,9\% do total. Há, no total de IES, uma presença expressiva de faculdades públicas e privadas (2.020), que equivalem a $82,5 \%$ do total das instituições existentes. Há a concentração de faculdades nas cidades do interior (2/3 do total, aproximadamente). As 199 universidades existentes no Brasil equivalem a $8,1 \%$ do total de IES e, dessas, a maioria é pública (106), equivalendo a $53,2 \%$ do total. As universidades públicas dividem-se, com aproximadamente $50 \%$ delas no interior e os outros $50 \%$ nas capitais. Há uma presença maior de universidades privadas nas cidades do interior. Dentre as IES privadas (2.152), predominam as faculdades (1.878), com o equivalente a $87,2 \%$ das instituições. No conjunto das faculdades públicas e privadas (2.020) predominam as privadas (1.878), com uma presença de 92,9\% de instituições.

O Quadro 2, a seguir, apresenta dados de cursos e matrículas da graduação nas modalidades presencial e à distância nas Licenciaturas, Bacharelados e Tecnólogos no ano de 2017. 


\section{Quadro 2 - Cursos e Matrículas de Graduação Presenciais e à Distância no Ensino Superior no Brasil por Categoria Administrativa - 2017}

\begin{tabular}{|l|c|c|c|c|c|c|c|c|c|c|}
\hline \multirow{2}{*}{$\begin{array}{l}\text { Categoria } \\
\text { Administrativa }\end{array}$} & \multicolumn{4}{|c|}{ Número de Cursos } & \multicolumn{4}{c|}{ Número de Matrículas } \\
\cline { 2 - 13 } & TOTAL & $\begin{array}{c}\text { Universi } \\
\text { Dade }\end{array}$ & $\begin{array}{c}\text { Centros } \\
\text { Universitá } \\
\text { rios }\end{array}$ & $\begin{array}{c}\text { Faculda } \\
\text { des }\end{array}$ & $\begin{array}{c}\text { IF e } \\
\text { CEFET }\end{array}$ & TOTAL & $\begin{array}{c}\text { Universi } \\
\text { Dade }\end{array}$ & $\begin{array}{c}\text { Centros } \\
\text { Universitá } \\
\text { rios }\end{array}$ & $\begin{array}{c}\text { Faculda } \\
\text { des }\end{array}$ & $\begin{array}{c}\text { IF e } \\
\text { CEFET }\end{array}$ \\
\hline Brasil & 35.308 & 15.729 & 5.618 & 12.584 & 1.449 & 8.286 .663 & 4.439 .917 & 1.594 .364 & 2.070 .197 & 182.185 \\
\hline Pública & 10.425 & 8.266 & 126 & 584 & 1.449 & 2.045 .356 & 1.720 .110 & 18.712 & 124.349 & 182.185 \\
\hline Federal & 6.353 & 4.884 & - & 20 & 1.449 & 1.306 .351 & 1.120 .804 & - & 3.362 & 182.185 \\
\hline Estadual & 3.487 & 3.190 & 11 & 286 & - & 641.865 & 563.636 & 1.076 & 77.153 & - \\
\hline Municipal & 585 & 192 & 115 & 278 & - & 97.140 & 35.670 & 17.636 & 43.834 & - \\
\hline Privada & 24.955 & 7.463 & 5.492 & 12.000 & - & 6.241 .307 & 2.719 .807 & 1.575 .652 & 1.945 .848 & - \\
\hline
\end{tabular}

Fonte: BRASIL/MEC/INEP - Sinopse Estatística da Educação Superior 2017

Disponível em http://inep.gov.br/web/guest/sinopses-estatisticas-da-educacao-superior. Acesso em 05 de maio de 2019.

Verifica-se no Quadro 2, consequentemente, número significativo de matrículas em IES privadas, com 75,3\% de matrículas no Brasil e 70,6\% do total de cursos. Também pode ser observado um percentual importante de matrículas em universidades (públicas e privadas), equivalendo a 53,5\% de matrículas na Educação Superior. As universidades públicas mantêm maior presença no campo em número de universidades (106), detêm o maior número de cursos (8.266), 803 cursos a mais em relação às universidades privadas (7.463), que são em menor número de instituições (93), porém mantêm menor número de matrículas (1.720.110) em relação à rede privada (2.719.807), com 999.697 matrículas a menos. Essa é uma questão que revela o caráter mercadológico das IES privadas, em que se supõem salas de aulas com grandes quantitativos de alunos, com a massificação dos cursos, inclusive com a implementação acentuada da Educação a Distância (EaD). Os dados revelam, também, o foco da rede privada em cursos e matrículas em faculdades, com já apontado anteriormente.

Dourado e Oliveira (2003, p. 80) explicitam que a Educação Superior desde a segunda metade dos anos 1990 "passou a receber o que comumente se identifica como um choque de mercado". Esse processo pode ser compreendido e denominado como mercantilização ou quase mercado $^{3}$ na Educação Superior, pois se verifica que o sistema de ensino superior passa a ser orientado e estruturado sob os interesses de empresários do campo do ensino privado nas sinalizações do mercado, o que se materializa por meio de isenções fiscais, financiamento 
de bolsas e processos de regulação mais flexíveis. No período de governo de Fernando Henrique Cardoso (1995-2002), as principais ações voltadas para a Educação Superior foram de cunho regulatório, instituindo uma base legal associada a provas e programas para avaliação dos estudantes e dos cursos; bem como reconfiguração do Conselho Nacional de Educação (CNE), com novas atribuições e o estabelecimento de padrões de referência para a organização acadêmica das IES.

Em outro sentido, observa-se que a flexibilização - seja na criação de IES seja na organização acadêmica e de cursos, além da maior liberdade na adoção de processos seletivos para ingresso na Educação Superior - apresenta-se como estratégia política para a expansão do sistema. "As universidades devem exercer sua autonomia institucional para propor cursos novos, flexibilidade curricular, caminhos de formação adaptados a cada realidade local" (BRASIL, 2002, p. 22). Nessa direção, as Diretrizes Curriculares Nacionais para a Formação de Professores da Educação Básica (BRASIL, 2002) afirmam:

Art. 14. Nestas Diretrizes, é enfatizada a flexibilidade necessária, de modo que cada instituição formadora construa projetos inovadores e próprios, integrando os eixos articuladores nelas mencionados. $\int 1^{\circ} \mathrm{A}$ flexibilidade abrangerá as dimensões teóricas e práticas, de interdisciplinaridade, dos conhecimentos a serem ensinados, dos que fundamentam a ação pedagógica, da formação comum e específica, bem como dos diferentes âmbitos do conhecimento e da autonomia intelectual e profissional. (BRASIL, 2002, p. 6, grifos nossos).

Nesta perspectiva, há a inclusão nos percursos formativos de novas formas e possibilidades de formação na Educação Superior, como os Bacharelados e Licenciaturas Interdisciplinares, por exemplo. Bacharelados Interdisciplinares (BIs) e similares são programas de formação em nível de graduação de natureza geral, que conduzem a diplomas, organizados por grandes áreas do conhecimento. O documento (BRASIL, 2002, p. 02, grifos do documento) justifica que: "A ideia de implantar uma formação em ciclos nas universidades brasileiras surge em um contexto marcado pela expansão das matrículas na Educação Superior”. Uma estratégia que incide sobremaneira no campo e lhe confere novas características, com IES distintas e com intenções e finalidades distintas também. O princípio da flexibilidade, adotado desde a Lei e Diretrizes e Bases da Educação Nacional (LDB), Lei no 9.394/1996, serviu de orientação para o processo de diversificação e diferenciação nos formatos institucionais, assim como da oferta de novos cursos considerados de ensino superior (pós-médio, graduação e pós-graduação), como os sequenciais, tecnológicos de educação profissional e mestrados profissionais, por exemplo. 
Sob outro aspecto, analisando-se um elemento comum que abriga as IES no campo, qual seja, a formação de indivíduos em nível superior, o art. 43 da Lei no 9.394/1996 institui a orientação à Educação Superior de um conjunto de finalidades para o atendimento desse objetivo comum. Essas finalidades devem ser desenvolvidas por todos os tipos de IES dos diversos sistemas de ensino, municipais, estaduais ou federal - universidades, centros universitários, faculdades e os Institutos Federais de Educação, Ciência e Tecnologia; devem ser dispositivos obrigatórios no Estatuto ou Regimento das IES e o Plano de Desenvolvimento Institucional (PDI) necessita contemplar estratégias, ações e metas nesse sentido, adaptadas à sua organização acadêmica.

A forma e a densidade do desenvolvimento de cada uma dessas finalidades dependem do tipo de IES, de sua missão e objetivos institucionais, definidos em lei, decreto ou normas específicas. A legislação tende a homogeneizar finalidades para todas as IES do campo; analisa-se, porém, que, a par de suas diferenciações, essas finalidades não se estendem em materialidade para todas (pesquisa, extensão, publicações, por exemplo). Sampaio (2014, p. 46), acentua:

Às universidades, a legislação outorga a indissociabilidade entre ensino, pesquisa e extensão, evidenciando aí a natureza da instituição. A Reforma Universitária (Lei n. 5.540) de 1968 elegeu o modelo de universidade (pública) de ensino, pesquisa e extensão para a formação de nível superior, reafirmado após o período autoritário pela Constituição de 1988, não obstante esta assegurasse que o ensino é livre à iniciativa privada. (grifos da autora).

Recortando-a das IES, compreende-se com Coelho (1999, p. 83) o espaço da universidade no campo, ou seja,

[...] como instituição que tem sua origem na sociedade e nela se enraíza, a universidade só pode ser compreendida em sua relação de interioridade com a sociedade. $O$ espaço em que se inscreve e realiza sua práxis é o espaço do social e político, a região da história. Sendo uma manifestação da vida social, a universidade não se estende a, não pode se estender à sociedade (à comunidade), pois não existe fora do social, do econômico e do político, nem mesmo pode estar dentro deles. (grifos nossos).

Sendo assim, como parte da sociedade e enraizada nela, a práxis universitária resulta da sociedade e, ao mesmo tempo, a produz, pois não está fora dela, devendo manter com a sociedade uma relação de interioridade. Portanto, sua natureza institucional e organização acadêmica estão em consonância com a sociedade, mas a universidade se revela não em conformidade ao instituído, apaziguada, mas, ao contrário, em movimento, em processos contínuos de 
ressignificações de seus agentes, em lutas e disputas (internas e externas) para pertencer e se manter no campo científico-universitário, ao mesmo tempo em que se estabelece com a crítica a essa mesma sociedade a qual pertence.

\section{CONSIDERAÇÕES FINAIS}

Neste estudo, avalia-se que os resultados relativos às atuais e novas faces do Estado brasileiro, oriundas de reformas recentes ou mesmo transformações mais significativas ocorridas no campo social decorrem de um conjunto de fatores de toda natureza, de contextos históricos, do volume de capital de seus agentes sociais e institucionais, do próprio poder do Estado, como aquele que mantém vitalizado, ou não, o poder da crença social em si. É possível compreender que o Estado, na atualidade, expressa e reafirma o ideário capitalista-liberal, bem como as suas contradições. Imprime, fortemente, uma força simbólica, resultado de lutas dos agentes dos campos sociais, daqueles que detêm maior volume de capital.

Nesse sentido, observam-se os campos em movimento como um lócus de relações conflitivas, porém com a expressão de práticas em prol de interesses da classe dominante neste determinado tempo, com estas condições objetivas e contexto histórico, econômico e social. O Estado deve ser compreendido como campo de disputas políticas, econômicas, sociais, ideológicas, seja em seu interior, na esfera administrativa, seja na abrangência de suas ações e relações, em que é marcado por disputas muito bem ancoradas em interesses de diferentes classes, estratos e grupos sociais. No caso brasileiro, observa-se um Estado cada vez mais vinculado à ideologia do capital, à conformidade de reprodução dessa ideologia e à sua materialização em novas regulações e ações que modificam sua ação no campo econômico e social.

Compreende-se que no Brasil, em especial, o modelo de Estado social não se instituiu, assim como sequer conseguiu reverter estruturalmente o nosso modelo de sociedade, desigual e excludente. O Brasil nunca foi nem é um centro dinâmico de desenvolvimento do capitalismo, da competição intercapitalista. A formação do Estado capitalista brasileiro é tardio e perseguiu o liberalismo tradicional, numa economia agrária e produtora de bens primários com transição lenta para a industrialização e para a o setor de serviços. $\mathrm{Na}$ atualidade, o Brasil passa por um processo de desindustrialização em que o desenvolvimento capitalista transcorreu simultaneamente à própria constituição do Estado moderno em conjunção com as particularidades de uma revolução burguesa desencadeadora do projeto de industrialização nacional. 
É possível analisar que as regulações dos sistemas público e privado no Brasil se impõem de tal forma que controlam o financiamento bem como as políticas para tal; promovem adequações em processos de distribuição da demanda entre o setor público e privado, tangenciando de forma tendenciosa a privilegiar o setor privado. O mercado educacional, em especial no que se refere ao corpo de IES privadas, torna-se algo próspero, pois gera lucros e ganhos altíssimos e se torna um campo de interesses não só do capital no Brasil, mas em todo o mundo, com a massificação e intensificação da mercantilização da educação. Em sentido mais específico, tem-se a intenção de formar profissionais mais sintonizados com a atual cultura empresarial, que visa aumentar à produtividade e ao empreendedorismo; daí, a necessidade de reformar o sistema educacional tornando-o mais ajustado às exigências produtivas e de autovalorização do capital no mundo das altas finanças.

As ações de regulação, regulamentação, financiamento, avaliação e flexibilização curricular do governo federal, dentre outras, vêm contribuindo para ampliar o mercado educacional, bem como desenvolver modelos de alocação de recursos baseados em desempenho, responsabilização e prestação de contas (accountability), o que contribui para uma maior concorrência interinstitucional e a adoção de princípios e parâmetros empresariais de gestão. Nesse cenário, as instituições privadas ganham corpo e substância para a concorrência no mercado educacional, ao passo que as instituições públicas são constrangidas a exercerem tal modus operandi nesse espectro.

Em outro sentido, compreende-se que as universidades, sobretudo públicas, vivenciam tensões e processos de reconfiguração de sua identidade, compromissos sociais e modus operandi na gestão e na produção do trabalho acadêmico. Os determinantes sociais atuais, sobretudo advindos do campo econômico e do campo político, vêm interferindo fortemente na gestão e na produção do trabalho acadêmico, ou seja, estabelecendo novas formas de indução e controle dos agentes que integram essas instituições sociais. Observa-se que os agentes institucionais, em particular as universidades, posicionam-se de formas distintas no campo, buscando manter ou mesmo transformar sua posição por meio de estratégias presentes no jogo moldado pelo Estado.

A diversificação e diferenciação foram princípios orientadores da reestruturação da Educação Superior adotados a partir da segunda metade dos anos 1990 que continuam a pautar o processo de reconfiguração das IES e, em particular das universidades, sobretudo nesta fase atual de orientação ultraneoliberal. As universidades que estão cada vez mais assemelhadas às organizações sociais, vão modelando-se para lidar com essas situações desafiadoras do ponto de vista da sobrevivência, especialmente em termos de redução dos 
recursos para manutenção e expansão. Os elementos históricos que a constituem como uma instituição social, todavia, indicam a necessidade de compreender e fazer a crítica das mudanças em curso, visando a superar o regime de acumulação com suas características atuais, as estruturas sociais constituídas historicamente, a hegemonia e os processos de dominação instituídos, o papel do Estado, os modos de regulação da vida econômica e social, a exemplo do neoliberalismo, tendo em vista a constituição de uma sociedade democrática, mais humana, mais digna e emancipada socialmente.

\section{REFERÊNCIAS}

BARreyro, G. B. Mapa do Ensino Superior Privado. Brasília : Instituto Nacional de Estudos e Pesquisas Educacionais Anísio Teixeira, 2008. 77 p. (Série Documental. Relatos de Pesquisa, ISSN 0140-6551; 37).

BOURDIEU, P. Os usos sociais da ciência: por uma sociologia clínica do campo científico. São Paulo: Editora UNESP, 2003. 86 p.

. Contrafogos: táticas para enfrentar a invasão neo-liberal; tradução de Lucy Magalhães, Rio de Janeiro: Jorge Zahar, Ed., 1998.

BOWE, Richard; BALL, Stephen J.; GOLD, Anne. Reforming Education and Changing Schools: case studies in policy sociology. London: Routledge, 1992.

BRASIL.MEC.INEP - Sinopse Estatística da Educação Superior, 2017. Disponível em http://inep.gov.br/web/guest/sinopses-estatisticas-da-educacaosuperior Acesso em 10/05/2019.

. Diretrizes Curriculares Nacionais para a Formação de Professores da Educação Básica, Resolução CNE/CP No 1, de 18 de Fevereiro de 2002. Disponível em: http://portal.mec.gov.br/seesp/arquivos/pdf/res1_2.pdf. Acesso em: 15/04/2019.

Decreto $\mathrm{n}^{\circ}$ 2.306, de 19 de agosto de 1997. Disponível em: http:// www.planalto.gov.br/ccivil_03/decreto/d2306.htm. Acesso em: 25/08/2 
Lei de Diretrizes e Bases da Educação Nacional (Lei n ${ }^{\circ} 9.394$ de 20 de dezembro de 1996). Disponível em: http://www.planalto.gov.br/ccivil_03/ Leis/19394.htm. Acesso em: 03/07/2017.

CARNOY, M. Estado e Teoria política. (Equipe de trad. PUCCAMP) $2^{a}$ ed. Campinas: Papirus, 1988, p. 19-62.

CHESNAIS, F. A mundialização do capital. São Paulo, Xamã Editora, 1996

COELHO, I. M. Realidade e utopia na construção da universidade. Goiânia: Editora UFG, 1999. (Memorial).

DARDOT, P.; LAVAL, C. A nova razão do mundo. SP: Editora Boitempo, 2017.

DIMAGGIO, P. J.; POWELL, W. W. A gaiola de ferro revisitada: isomorfismo institucional e racionalidade coletiva nos campos organizacionais. RAERevista de Administração de Empresas, vol. 45, n. 2, abr-jun 2005.

DOURADO, L. F.; OLIVEIRA, J. F. A reforma da Educação Superior e os seus desdobramentos nas universidades federais: tópicos para um debate. Campo Grande: UCDB, Série Estudos, n. 16, p. 79 a 92, jul/dez 2003.

HARVEY, D. O enigma do capital e as crises do capitalismo; tradução de João Alexandre Peschanski. São Paulo, SP: Boitempo, 2011.

LEITE, D. Modelos institucionais, avaliação e isomorfismos In: Modelos Institucionais de Educação Superior, Brasília: Instituto Nacional de Estudos e Pesquisas Educacionais Anísio Teixeira, 2006, p. 165 - 195 (Coleção Educação Superior em Debate; v. 7).

MANCEBO; SILVA JR, J. R.; OLIVEIRA, J. F. Políticas, Gestão e Direito a Educação Superior: Novos Modos de Regulação e Tendências em Construção. Revista Acta Scientiarum. Education, v. 40, e37669, 2018.

MARQUES, W. Expansão e oligopolização da Educação Superior no Brasil. Avaliação (Campinas), Sorocaba , v. 18, n. 1, p. 69-83, Mar. 2013

NEVES, C. E. B. Diversificação do sistema de educação terciária: um desafio para o Brasil. Tempo soc., São Paulo, v. 15, n. 1, p. 21-44, Apr. 2003. 
POCHMANN, M. Estado e capitalismo no Brasil: a inflexão atual no padrão das políticas públicas do ciclo político da nova república. Educ. Soc., Campinas, v. 38,n. 139,p. 309-330, Jun. 2017.

SAMPAIO, H. Diversidade e diferenciação no ensino superior no Brasil: conceitos para discussão. SP: ANPOCS, RBCS Vol. 29 n 84 fevereiro/2014.

H. SAMPAIO, H. O setor privado de ensino superior no Brasil: continuidades e transformações. Campinas: Revista Ensino Superior UNICAMP, 2011, outubro, ano 2, nº4. Campinas: Revista Ensino Superior UNICAMP, 2011, outubro, ano $2, \mathrm{n}^{\circ} 4$.

SAMPAIO, H. Ensino superior no Brasil - o setor privado. São Paulo: Fapesp/ Hucitec, 2000.

SAVIANI, Dermeval. Da nova LDB ao Novo Plano Nacional de Educação: por uma outra política educacional. Campinas: Autores Associados, 2000.

SGUISSARDI, V. Educação Superior no Brasil - democratização ou massificação mercantil? Educ. Soc., Campinas, v. 36, nº 133, p. 867-889, out.-dez., 2015.

. Universidade Brasileira no Século XXI - desafios do presente. SP: Cortez, 2009.

SILVA JR; SGUISSARDI, V. Novas faces da Educação Superior no Brasil Reforma do Estado e mudanças na produção. SP: Cortez, 2001.

SOUSA, S. M. Z. L.; OLIVEIRA, R. P. Políticas de avaliação da educação e quase ercado no Brasil. Educação e Sociedade, Campinas, v. 24, n. 84, p.873895, set.2003.

TEIXEIRA, R. A. Capital e colonização: a constituição da periferia do sistema capitalista mundial. Estudos Econômicos (São Paulo), São Paulo, v. 36, n. 3, p. 539-591, sep. 2006. ISSN 1980-5357.

WOOD, E. M. Democracia contra o capitalismo - a renovação do materialismo histórico. SP: Boitempo, 2011. 
SYLVANA DE OLIVEIRA BERNARDI NOLETO é Doutora em Educação pela Universidade Federal de Goiás (UFG). Professora da Universidade Estadual de Goiás (UEG) e da Pontifícia Universidade Católica de Goiás (PUC Goiás). E-mail: sylvana.bernardi@gmail.com

JOÃO FERREIRA DE OLIVEIRA é Doutor em Educação pela Universidade de São Paulo (USP). Professor do Programa de Pós-graduação em Educação da UFG. Pesquisador CNPq. E-mail: joao.jferreira@gmail.com

ORCID: https://orcid.org/0000-0002-4135-6340

Recebido em junho de 2019

Aprovado em julho de 2019 